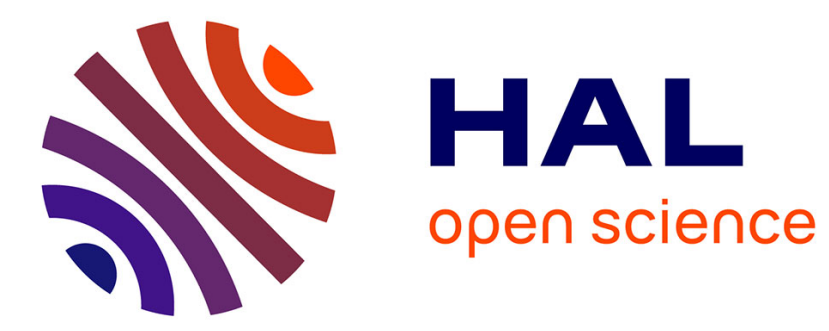

\title{
Epilepsy in multiple sclerosis as a network disease
}

\author{
Mihaela Bustuchina Vlaicu
}

\section{To cite this version:}

Mihaela Bustuchina Vlaicu. Epilepsy in multiple sclerosis as a network disease. Multiple Sclerosis and Related Disorders, 2019, 36, pp.101390. 10.1016/j.msard.2019.101390 . hal-02530751

\section{HAL Id: hal-02530751 \\ https://hal.sorbonne-universite.fr/hal-02530751}

Submitted on 3 Apr 2020

HAL is a multi-disciplinary open access archive for the deposit and dissemination of scientific research documents, whether they are published or not. The documents may come from teaching and research institutions in France or abroad, or from public or private research centers.
L'archive ouverte pluridisciplinaire HAL, est destinée au dépôt et à la diffusion de documents scientifiques de niveau recherche, publiés ou non, émanant des établissements d'enseignement et de recherche français ou étrangers, des laboratoires publics ou privés. 


\title{
Epilepsy in multiple sclerosis as a network disease
}

\author{
Mihaela Bustuchina Vlaicu, $\mathrm{MD}, \mathrm{PhD}^{1,2}$ \\ ${ }^{1}$ Neurosurgery department, Hospital Pitié Salpêtrière, Paris, France \\ ${ }^{2}$ INSERM, U0955
}

E-mail: vlaicu.mihaela@gmail.com

\begin{abstract}
This is a review paper, essentially a commentary with summary of literature that actualizes the problem of epilepsy in patients with multiple sclerosis. There is a bidirectional relation between multiple sclerosis and epilepsy. A possible associate pathophysiological pathway is considered. In multiple sclerosis, a combination of grey matter involvement and inflammation could influence epileptogenesis. Patients with multiple sclerosis have individual profiles and an inter-individual variability of epileptogenicity. No treatment guidelines have been specified for these patients. We postulate that an epileptic manifestation means a relapse or an aggravation of the inflammatory process. In this condition, over time, this symptom could integrate into the Expanded Disability Status Scale. Epileptogenesis is an active process and an interesting question is if disease-modifying therapy in multiple sclerosis can prevent, or mitigate, epilepsy. In light of the latest knowledge of the inflammatory process in epilepsy, the possibility of preventing epileptogenesis with actual treatment of MS is emphasized. We would argue that it is a strong argument for starting treatment quicker for both diseases. Over the last few years, the concepts of epilepsy have completely changed. The model of epilepsy in multiple sclerosis can currently be regarded as a network disease and this new concept can have a highly significant clinical impact.
\end{abstract}

Keywords: multiple sclerosis, seizure, treatment, epileptogenesis, network. 


\section{Introduction}

Multiple sclerosis is a complex and heterogeneous demyelinating disease of the central nervous system. The incidence and prevalence of multiple sclerosis patients ranges from $1.5 \%$ to 7.8\% (Lund et al, 2014).

\section{Is epilepsy in multiple sclerosis really a secondary epilepsy?}

Epileptic attacks can affect patients at any point during the course of multiple sclerosis. In fact, it is not uncommon for epilepsy to be the first manifestation in the diagnosis of multiple sclerosis. However, most frequently, seizures occur following the onset of the disease. The association with the clinical form, or the disease course, is largely unknown (Gasparini et al, 2017). Given the anatomical variability of the demyelinating lesions, all types of seizures have been previously noted in multiple sclerosis patients. Particular attacks of myoclonic, dysphasic, musicogenic seizures and partial continuous epilepsy are rare. Patients with MS can have an increased risk of status epilepticus.

There was an increase in the frequency of seizures observed in multiple sclerosis, but we still haven't been able to accurately describe the exact pathological substrate (Ciccarelli et al, 2014). Several hypotheses have been mentioned. Anatomopathological findings and magnetic resonance imaging metrics have suggested that cortical and juxtacortical inflammation (Martinez-Lapiscina et $a l, 2013$ ), demyelination (Lapato et al, 2017) and gray matter damage (Van Munster et al, 2015) may be responsible for the development of epileptic seizures. Edema associated with acute multiple sclerosis lesions and tumefactive white matter lesions may cause cortical hyper excitability (Calabrese et al, 2008). New or strategically placed cortical, hippocampal and parahippocampal lesions, reduced the cortical thickness of the middle temporal gyrus and it has been noted that inhibitory GABA interneuron cell loss may cause seizures even at the onset of multiple sclerosis (Nicholas et al, 2016). Very few reports in human and animal literature have described the role of the brainstem in epileptogenicity (Papathanasiou et al, 2010). Glia may provide a biomarker of epileptogenesis 
(Devinsky et al, 2013). Many other causal factors may be involved in the development of seizures, but this hypothetical correlation remains to be proved.

Using higher field strengths and specific sequences, the detection of cortical lesions was increased: double inversion recovery, diffusion, magnetization transfer, gradient echo plural contrast imaging, functional and high field magnetic resonance imaging (3,7 and 9,4 Tesla). Neuroaxonal damage, astrogliosis and demyelination, can be measured with magnetic encephalography, density imaging or myelin water fraction. White and gray matter damage can induce concurrent increases, and decreases, in functional connectivity (Tewarie et al, 2018).

\section{It should never be forgotten that epileptogenesis is also an active process}

It is not easy to obtain evidence of the relationship between the seizures, the cortical plaque and the epileptic focus. Electrical anomalies are extremely labile in time and space and not always specific. A periodic lateralized epileptiform discharge, or a non-convulsive electrical state, can sometimes be found. The epileptogenic potential of smaller cortical lesions is often less evident, and the electroencephalogram defined onset zone frequently did not match lesion locations. If we consider the many lesions of the white and gray matter, it is difficult, or even impossible, to establish exactly at what point an epileptic discharge starts. Frequently, the patients have not had antiepileptic treatments and, with that being he case, we can imagine an increase of epileptic activity, with an extension of the phenomena of epileptogenesis. To understand epileptogenesis, it is necessary to control the processes that can lower the epileptogenic threshold (such as the microglial activation and inflammation). In patients with MS, it is possible that the seizure activity can induce inflammatory changes that favor the worsening of the auto-immune demyelinating disease. For many years, pre-clinical, and clinical, epilepsy researchers have almost only been focused on neuronal alterations. However, in recent years, it is clear that epilepsy might be associated with non-neuronal alterations. Glial cells, cytokines, vascular alterations and leukocyte trafficking can play key roles in both the initiation, and the maintenance, of epileptic activity.

Epileptic activity can contribute to the worsening of multiple sclerosis and, conversely, multiple sclerosis can contribute to the induction of epilepsy. Each crisis can induce a true vascular inflammation and inflammatory mechanisms may be the cause of epilepsy (Vezzani et al, 2005). 


\section{A bidirectional relation between multiple sclerosis and epilepsy. How is it possible to maintain a good balance between both entities?}

If we consider that there is a bidirectional relation between multiple sclerosis and epilepsy, in order to maintain a good balance, we must treat both entities. Information on antiepileptic drug treatments and seizure outcomes is scarce. Research on the management of seizures in patients with multiple sclerosis is inconclusive. Pivotal clinical trials with Interferon- $\beta$ medications and Glatiramer acetate have not supplied the answer and the relationship of the seizures with these medications is regarded as indeterminate. It is highly plausible that damaged myelin sheaths generated with the progression of epilepsy have played a certain facilitating role in the development, or aggravation, of epileptic seizures. For example, the preventive administration of Glatiramer acetate has a protective effect on the hippocampus and on cerebral cortex myelin tissue (Glatiramer acetate has reduced epileptic seizures induced by pentylenetetrazol in rats) (You et al, 2013). However, with the exception of interferons and Glatiramer acetate, what role do the other background treatments used in multiple sclerosis epilepsy play? The current understanding of the pathogenesis of seizures and epilepsy suggests a more general application of Natalizumab and anti-adhesion therapy in epilepsy. A recent observation has shown successful treatment of refractory epilepsy in a 24-year-old patient with multiple sclerosis with natalizumab (Fabene et al, 2013). Sphingosine 1-phosphate (S1P) and its receptors might also represent a suitable novel target in light of their involvement in neuroinflammation. It seems that Fingolimod has the potential to be developed as a disease modifying, anti-convulsive, and neuroprotective therapy in pharmacoresistant Temporal lobe epilepsy patients (Leo et al, 2017; Pitsch et al, 2018). In the therapeutic management of epilepsy, there are a great number of antiepileptic drugs. Unfortunately, anticonvulsants provide only symptomatic effects and none have demonstrated modifying effects on the disease, particularly in multiple sclerosis. All classical antiepileptic drugs could have anti-inflammatory effects: Valproate affects immune cells (including inhibiting natural killer cells) (Soria-Castro et al, 2019), Carbamazepine and Levetiracetam can reduce inflammatory mediators in glial cell cultures, and Vigabatrin can cause changes in the immune system, by damaging its cellular or humoral responses 2018 (Stefanović et al, 2018 ; Perucca et al, 2019). Concomitant treatment for multiple sclerosis should also be considered: Baclofen, 
Aminopyridine, and Fampridine may increase the risk of seizures in multiple sclerosis patients. Concomitant administration of Melatonin with Valproate would be expected to decrease seizure susceptibilities further (Zaccara, Perruca 2014). In the absence of evidence of efficacy and the tolerance of different antiepileptic drugs from prospective studies in multiple sclerosis, the selection of antiepileptic drug treatment should be based upon general recommendations (the type of seizure, the tolerability of the drug and the comorbidity) (Koch et al, 2009).

\section{Discussions}

The clinical symptoms can be analyzed in the context of both structural and functional changes in the brain. Cortical demyelination and inflammation are attractive possibilities for pathological substrates, but how cortical lesions atrophy, individually or in conjunction, to contribute to the development of clinical symptoms remains to be elucidated. Increasing our knowledge concerning the role of inflammation in epilepsy progression, and multiple sclerosis inflammation, is evident, but epileptic mechanisms are very complex! Where do seizures start? Over the past decades, a sustained research effort has been undertaken to identify the so-called "epileptogenic zone", but this zone is most often organized as an extended network. (Kahane et al, 2006; Jehi et al, 2018). So, over the last few years, the concepts of epileptic diseases have changed completely. Clinical observations support the large neural network concept of human epilepsy. The well-formulated definition for "epilepsy networks" comes from Spencer: "A network is a functionally and anatomically connected, bilaterally represented, set of cortical and subcortical brain structures and regions in which activity in any one part affects activity in all the others" (Spencer, 2002). To localize and to characterize the cerebral areas involved in the genesis and the propagation of focal epileptic seizures, the brain structures can be explored with intracerebral electrodes. Certainly, patients with multiple sclerosis offer individual profiles of epileptogenicity and important inter-individual variabilities. Quantitative intracranial electroencephalogram analyses, Positron Emission Tomography, Ictal Singl Positron Emission Tomography, functional Magnetic Resonance Imaging, connectivity analyses and dynamic computational modeling have helped to formulate the concept of epileptic networks. In reality,

multiple sclerosis seizures are very rarely, if ever deeply investigated when compared to cases of epileptic disease or secondary epilepsy. Of course, it is difficult to propose this invasive investigation 
to patients with multiple sclerosis. Fortunately, a good analysis of seizure semiology is a key diagnostic tool to help us. That truly reflects the genesis and the propagation of epileptic phenomena over a vast network. We find it is very interesting that during the course of this disease, patients with multiple sclerosis exhibit decreased structural and functional connectivity (Schoonheim et al, 2013; Solana et al, 2018). To maintain the functions, it will be necessary to reorganize the networks (Liu et al, 2018). It is increasingly evident that there are bidirectional relations between multiple sclerosis and epilepsy. Brain organization, a multitude of complex networks linked together, does not help us to explain the epileptic process in a simple manner. The exact cause of the huge variations of seizures between multiple sclerosis patients remains unclear. It is probable that a high epileptogenicity of multiple sclerosis pathology could reflect a dominance of brain inflammatory processes but, as we have already mentioned, even though demyelinating lesions are not numerous, they can be located in strategic places which could explain epileptic seizures. It has been postulated that the appearance, or not, of seizures in multiple sclerosis could indicate a distinct clinical phenotype of multiple sclerosis (Kavčič et al, 2017). Additional research is required to elucidate and explain epileptogenesis in chronic demyelination with seizures (Pack et al, 2018). As we have already mentioned, it should be noted that epileptogenesis is an active process that could evolve over the years. Therefore, we would argue that it is a strong argument to start this treatment quickly. Little information is available on optimal antiepileptic drug treatments and their epilepsy outcomes (Dagiasi et al, 2018). It is also important to mention that there is an individual variability in the response to antiepileptic drugs. A population-based register study could help (Burman, 2017), but unfortunately, at present, no treatment guidelines have been specified for patients with multiple sclerosis and epilepsy. The efficacy of antiepileptic drugs, together with a positive response of intravenous steroid therapy, have been reported. It is important to start anti-inflammatory therapy early when there is evidence that seizures are secondary to new cortical/subcortical lesions. Fortunately, the vast majority of patients suffering from multiple sclerosis receive immunomodulation or immunosuppression treatments. This could explain the "low" prevalence of epilepsy. Studies of the prognosis of epilepsy in patients with multiple sclerosis have given contradictory results. Is epilepsy in multiple sclerosis really secondary epilepsy or a classic, clinical sign of this disease? It depends how we look at, and interpret, the two notions. We postulate that an epileptic manifestation means a relapse or, generally, an aggravation of an inflammatory process. In this case, in the future, this symptom could integrate into the Expanded Disability Status Scale. 


\section{Conclusion}

Although epilepsy has been seen and described in connection with multiple sclerosis for more than 150 Years, it was only in 2018 that this subject has come back into the limelight. It is still always an exciting subject though also quite controversial. We consider that the model of epilepsy in multiple sclerosis can also be regarded as a network disease. This new concept can have a truly significant clinical impact, because the clinical symptoms can be analyzed in the context of both structural and functional changes in the brain. Currently, the translational studies aimed at elucidating the pathophysiological processes underlying multiple sclerosis epileptogenesis are limited. To understand this process, we need to ensure a close and truly multi-disciplinary collaboration. 


\section{References}

Burman J, Zelano J. Epilepsy in multiple sclerosis: A nationwide population-based register study. Neurology 2017 ; 89 (24) : 2462-2468.

Calabrese M, De Stefano, Atzori M, Bernardi V, Mattisi I, Barachino L et al. Extensive cortical inflammation is associated with epilepsy in multiple sclerosis. J Neurol 2008; 255: 581-586.

Ciccarelli O, Barkhof F, Bodini B, De Stefano N, Golay X, Nicolay K et al. Pathogenesis of multiple sclerosis: insights from molecular and metabolic imaging. Lancet Neurol 2014; 13: 807- 22.

Dagiasi I, Vall V, Kumlien E, Burman J, Zelano J. Treatment of epilepsy in multiple sclerosis. Seizure 2018 May ; 58; 47-51.

Devinsky O, Vezzani A, Najjar S, De Lanerolle NC, Rogawski MA. Glia and epilepsy: excitability and inflammation. Trends Neurosci. 2013 Mar; 36 (3):174-84.

Fabene PF, Laudanna C, Constantin G. Leukocyte trafficking mechanisms in epilepsy. Molecular Immunology 2013; 55; 100- 104.

Gasparini S, Ferlazzo E, Ascoli M, Sueri C, Cianci V, Russo C et al. Risk factors for unprovoked epileptic seizures in multiple sclerosis: a systematic review and meta-analysis. Neurol Sci. 2017 Mar; 38(3): 399-406.

Jehi L. The Epileptogenic Zone: Concept and Definition. Epilepsy Curr. 2018 Jan-Feb; 18(1):1216.

Kahane P, Landre E, Minotti L, Francione S, Ryvlin P. The Bancaud and Talairach view on the epileptogenic zone: A working hypothesis. Epileptic Disord 2006; 8: S16-26.

Kavčič A, Hofmann WE. Unprovoked seizures in multiple sclerosis: Why are they rare? Brain and Behavior. 2017; 7: e00726.

Koch MW, Polman SK, Uyttenboogaart M, De Keyser J. Treatment of seizures in multiple sclerosis. Cochrane Database Syst Rev. 2009 Jul 8;(3): CD007150.

Lapato AS, Szu JI, Hasselmann JPC, Khalaj AJ, Binder DK, Tiwari-Woodruff SK. Chronic demyelination-induced seizures. Neuroscience. 2017 Mar 27; 346:409-422.

Leo A, Citraro R, Marra R, Palma E, Paola EDD, Constanti A et al. The Sphingosine 1Phosphate Signaling Pathway in Epilepsy: A Possible Role for the Immunomodulator Drug Fingolimod in Epilepsy Treatment. CNS Neurol Disord Drug Targets. 2017; 16 (3): 311-325.

Liu Y, Duan Y, Dong H, Barkhof F, Li K, Shu N et al. Disrupted Module Efficiency of Structural and Functional Brain Connectomes in Clinically Isolated Syndrome and Multiple Sclerosis. Frontiers in Human Neuroscience. 2018 Apr 10; 12:138. 
Lund, C., Nakken, K. O., Edland, A., \& Celius, E. G. Multiple sclerosis and seizures: Incidence and prevalence over 40 years. Acta Neurologica Scandinavica 2014; 130: 368-373.

Martínez-Lapiscina EH, Ayuso T, Lacruz F, Gurtubay IG, Soriano G, Otano M et al. Corticojuxtacortical involvement increases risk of epileptic seizures in multiple sclerosis. Acta Neurol Scand 2013; $128: 24-31$.

Nicholas R, Magliozzi R, Campbell G, Mahad D, Reynolds R. Temporal lobe cortical pathology and inhibitory GABA interneuron cell loss are associated with seizures in multiple sclerosis. Mult Scler $\mathrm{J}$ 2016 ; 22 : 25-35.

Pack A. Is There a Relationship Between Multiple Sclerosis and Epilepsy? If So What Does It Tell Us About Epileptogenesis? Epilepsy Curr. 2018 Mar-Apr; 18(2): 95-96.

Papathanasiou ES, Pantzaris M, Myrianthopoulou P, Kkolou E, Papacostas SS. Brainstem lesions may be important in the development of epilepsy in multiple sclerosis patients: an evoked potential study. Clin Neurophysiol $2010 ; 121(12): 2104-10$.

Perucca E. Antiepileptic drugs: evolution of our knowledge and changes in drug trials. Epileptic Disord. 2019 Aug 1;21(4):319-329.

Pitsch J, Kuehn C J, Gnatkovsky V, Müller JA, van Loo KMJ, de Curtis M et al. Antiepileptogenic and Anti-convulsive Effects of Fingolimod in Experimental Temporal Lobe Epilepsy. Molecular Neurobiology 2018 Jun 22: 1-16.

Schoonheim MM, Geurts JJ, Landi D, Douw L, van der Meer ML, Vrenken H et al. Functional connectivity changes in multiple sclerosis patients: a graph analytical study of MEG resting state data. Hum Brain Mapp. 2013 ; 34 (1) :52-61.

Solana E, Martinez-Heras E, Martinez-Lapiscina EH, Sepulveda M, Sola-Valls N, Bargalló N et al. Magnetic resonance markers of tissue damage related to connectivity disruption in multiple sclerosis. Neuroimage Clin. 2018 Jul 12; 20 :161-168.

Soria-Castro R, Schcolnik-Cabrera A, Rodríguez-López G, Campillo-Navarro M, Puebla-Osorio N, Estrada-Parra $S$ et al. Exploring the Drug Repurposing Versatility of Valproic Acid as a Multifunctional Regulator of Innate and Adaptive Immune Cells. J Immunol Res. 2019: 9678098.

Spencer SS. Neural networks in human epilepsy: evidence of and implications for treatment. Epilepsia. 2002 Mar; 43(3):219-27.

Stefanović S, Janković SM, Novaković M, Milosavljević M, Folić M. Pharmacodynamics and common drug-drug interactions of the third-generation antiepileptic drugs. Expert Opin Drug Metab Toxicol. 2018 Feb;14(2):153-159.

Tewarie P, Steenwijk MD, Brookes MJ, Uitdehaag BMJ, Geurts JJG, Stam CJ et al. Explaining the heterogeneity of functional connectivity findings in multiple sclerosis: An empirically informed modeling study. Hum Brain Mapp. 2018 ; 39 (6) : 2541-2548.

Van Munster CE, Jonkman LE, Weinstein HC, Uitdehaag BM, Geurts JJ. Gray matter damage in multiple sclerosis: Impact on clinical symptoms. Neuroscience 2015 ; $303: 446-61$. 
Vezzani A, Granata T. Brain inflammation in epilepsy: experimental and clinical evidence. Epilepsia 2005; 46:1724-1743.

You Y, Zhao Y, Bai H, Liu Z, Meng F, Zhang H et al. Glatiramer acetate, an anti-demyelination drug, reduced rats'epileptic seizures induced by pentylenetetrazol via protection of myelin sheath. European Journal of Pharmaceutical Sciences 2013; $49: 366-370$.

Zaccara G, Perucca E. Interactions between antiepileptic drugs, and between antiepileptic drugs and other drugs. Epileptic Disord. 2014 Dec; 16(4):409-31. 
Conflict of Interest Statement: The author declares that all research was conducted in the absence of any commercial or financial relationships that could be construed as a conflict of interest. 


\section{Highlights}

- $\square \quad$ It is a review paper that actualizes the problem of epilepsy in patients with MS.

- $\quad$ Patients with MS have an interindividual variability of epileptogenicity.

- $\quad \square \quad$ The model of epilepsy in MS can be regarded as a network disease.

- $\square \quad$ This is a strong argument to start quicker a treatment for MS and for epilepsy.

- $\square \quad$ Epilepsy could integrate in the Expanded Disability Status Scale (EDSS). 